\title{
Fatal gadolinium-induced encephalopathy following accidental intrathecal administration: a case report and a comprehensive evidence-based review
}

\author{
David Anthony Provenzano, ${ }^{1}$ Zachary Pellis, ${ }^{1}$ Leonard DeRiggi ${ }^{2}$
}

${ }^{1}$ Pain Diagnostics and Interventional Care, Sewickley, Pennsylvania, USA ${ }^{2}$ Brighton Radiology Associates, Sewickley, Pennsylvania, USA

\section{Correspondence to} Dr David Anthony Provenzano, Pain Diagnostics and Interventional Care, Sewickley, PA 15143, USA: davidprovenzano@hotmail.com

This work was presented in part at: American Society of Regional Anesthesia and Pain Medicine 16th Annual Meeting, Lake Buena Vista, Florida, USA, November 2017.

Received 29 January 2019 Revised 4 March 2019 Accepted 8 March 2019 Published Online First 25 April 2019

\section{SLinked}

- http://dx.doi.org/10.1136/ rapm-2019-100603

\section{Check for updates}

(C) American Society of Regional Anesthesia \& Pain Medicine 2019. No commercial re-use. See rights and permissions. Published by BMJ.

To cite: Provenzano DA, Pellis Z, DeRiggi L. Reg Anesth Pain Med 2019;44:721-729.

\section{ABSTRACT}

Gadolinium-based contrast agents (GBCAs) have been suggested as off-label alternatives to iodinebased contrast agents for fluoroscopic imaging during interventional pain procedures. We report a case of accidental intrathecal administration of a GBCA during a neuraxial interventional pain procedure leading to acute gadolinium neurotoxicity, which resulted in encephalopathy and ultimately death. To our knowledge, it is the first published case of fatal intrathecal gadolinium-induced encephalopathy and the first published case of intrathecal gadoteridol causing serious neurologic complications. In addition, the case presented here is placed in context with an associated comprehensive, evidence-based review of the use of gadolinium in interventional pain procedures, addressing gadolinium chemistry and pharmacologic properties, neurotoxicity and radiology. Physicians must be aware that gadolinium poses a significant risk of acute neurotoxicity even in small doses. Until further safety research is performed, GBCAs should not be considered a safe alternative for use in neuraxial interventional spine procedures when there is a risk of inadvertent intrathecal administration.

\section{INTRODUCTION}

Gadolinium is a metallic element from the lanthanide series prescribed for use as a contrast agent with MRI. ${ }^{12}$ Since the 1980 s, gadolinium-based contrast agents (GBCAs) have been administered via the intravenous route prior to MRIs and currently are used in approximately 35\% of all MRI examinations. ${ }^{3}$ Although considered relatively safe in individuals with normal renal function, the administration of intravenous GBCAs has been associated with adverse events. ${ }^{4}$ Recently, more attention has been placed on gadolinium toxicity, including nephrogenic systemic fibrosis (NSF) and tissue and brain deposition following intravenous use. ${ }^{367}$

GBCAs are also used off label as alternatives to iodine-based contrast agents to assist with visualization in interventional pain procedures in individuals with known hypersensitivity reactions to iodine. ${ }^{8}$ Although the practice of injecting GBCAs into the neuraxial space (ie, epidural and intrathecal areas) is not Food and Drug Administration (FDA)-approved, published articles and leading pain management textbooks have suggested GBCAs as alternatives to iodine-based contrast agents. ${ }^{9-12}$ The utilization of GBCAs for interventional pain procedures has not been extensively studied, and the associated risks have received less attention than other intravenous GBCA-related complications. Lately, safety concerns have been raised regarding GBCA utilization for interventional pain management procedures, especially when there is a risk of intrathecal administration. ${ }^{12} 13$

Based on animal models and human case studies, the off-label use of a GBCA in the intrathecal space either intentionally or unintentionally may pose a significant risk of acute neurotoxicity. ${ }^{12} 1415$ We report a case of inadvertent GBCA intrathecal administration following a neuraxial interventional pain procedure leading to neurotoxicity, encephalopathy, and death. To our knowledge, this is the first published case of fatal intrathecal gadolinium-induced encephalopathy and the first published case of intrathecal gadoteridol (ProHance) causing serious complications secondary to acute neurotoxicity. In addition to reporting this case, we provide a comprehensive review of the use of gadolinium in interventional pain procedures, addressing its radiologic and pharmacologic properties and neurotoxicity, with a focus on neuraxial use for interventional pain procedures.

\section{CASE REPORT}

The deceased patient's family consented to the publication of this report. This procedure was not performed by the authors and occurred at an outside outpatient surgery center. A 67-year-old woman with a history of lumbar spinal stenosis secondary to ligamentum flavum hypertrophy presented for a minimally invasive lumbar decompression (MILD). Her medical history was significant for hypothyroidism, hypertension and sleep apnea. It was her second MILD procedure in 4 months. Because of the patient's reported iodine allergy, a GBCA (ie, gadoteridol) was used for fluoroscopic guidance in both MILD procedures for enhanced visualization. Her first MILD procedure was completed without complications. Gadoteridol was also used for her second MILD procedure in order to create the epidurogram. Following the introduction of an 18-gauge Tuohy needle into the epidural space at L5-S1, $5 \mathrm{~mL}$ of gadoteridol were injected with reported confirmation of epidural flow. The pain physician's operative note indicated the MILD procedure was completed without any observed complications.

In the recovery room immediately after the completion of the procedure, the patient experienced a severe headache, mental status changes, 

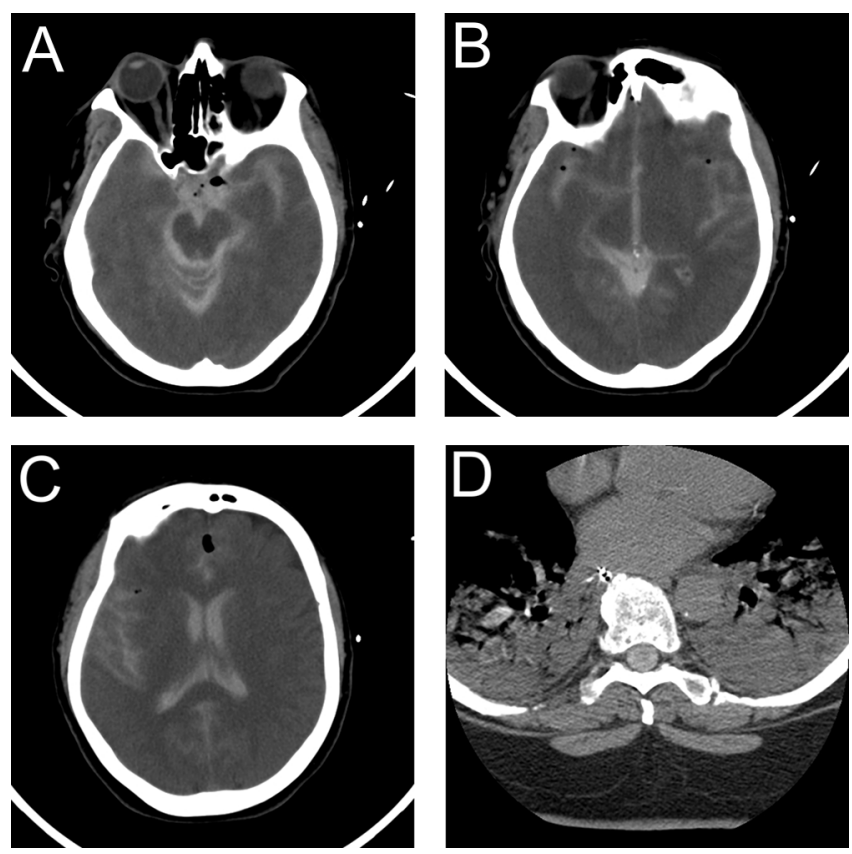

Figure 1 CT head images from postoperative day 0. Cranial CT images demonstrate gadolinium (hyperattenuation) in the basal cisterns (A), third ventricle (B), lateral ventricles, and right sylvian fissure (C). Spine CT imaging taken of the lower thoracic spinal canal displays gadolinium in the intrathecal space (D).

apnea, agitation and increased muscle tone in her arms and legs. Due to her declining condition, she was urgently sent to a hospital for further treatment.

On arrival at the hospital, the patient demonstrated signs of distress including twitching in her eyes and tongue, thrashing and crying out. She also displayed decreased respirations and myoclonic activity. About 20 min after arrival, the patient experienced wide-complex pulseless tachycardia. The patient was intubated and underwent successful cardiopulmonary resuscitation. After 4 min, normal vital signs were restored. The patient then experienced a fever of $103{ }^{\circ} \mathrm{F}\left(39.4^{\circ} \mathrm{C}\right)$ that did not resolve with acetaminophen and ice packs. The patient also began experiencing seizures that occurred approximately every $20 \mathrm{~min}$. A CT scan of the head was obtained, and the images displayed hyperattenuation in the subarachnoid space that was originally misinterpreted as subarachnoid hemorrhage (figure $1 \mathrm{~A}, \mathrm{~B}$ and $\mathrm{C}$ ). Because of the potential necessity for neurosurgical services, the patient was flown via emergency helicopter to another hospital.

Additional CT and MRI images were taken at this hospital (figures 1D and 2). Reviewing these images and the images taken at the previous hospital, the medical team determined that the images did not indicate a subarachnoid hemorrhage but rather showed an accumulation of GBCA within the intrathecal cerebral spinal fluid (CSF). A diagnosis of encephalopathy secondary to intrathecal injection of a GBCA was made. Brain imaging also revealed infarctions that suggested anoxic brain injury (figure 2). At this point, the neurosurgical team determined it was too late to drain the patient's CSF. The patient's condition continued to deteriorate, culminating in multisystem organ failure and coma. Two weeks after her MILD procedure, the patient was placed into hospice care where she died 4 days later (18 days after the procedure).

The autopsy found no evidence of subarachnoid hemorrhage. Large cortical infarcts were found in the right occipital and parietal lobes. The right insular cortex displayed infarction
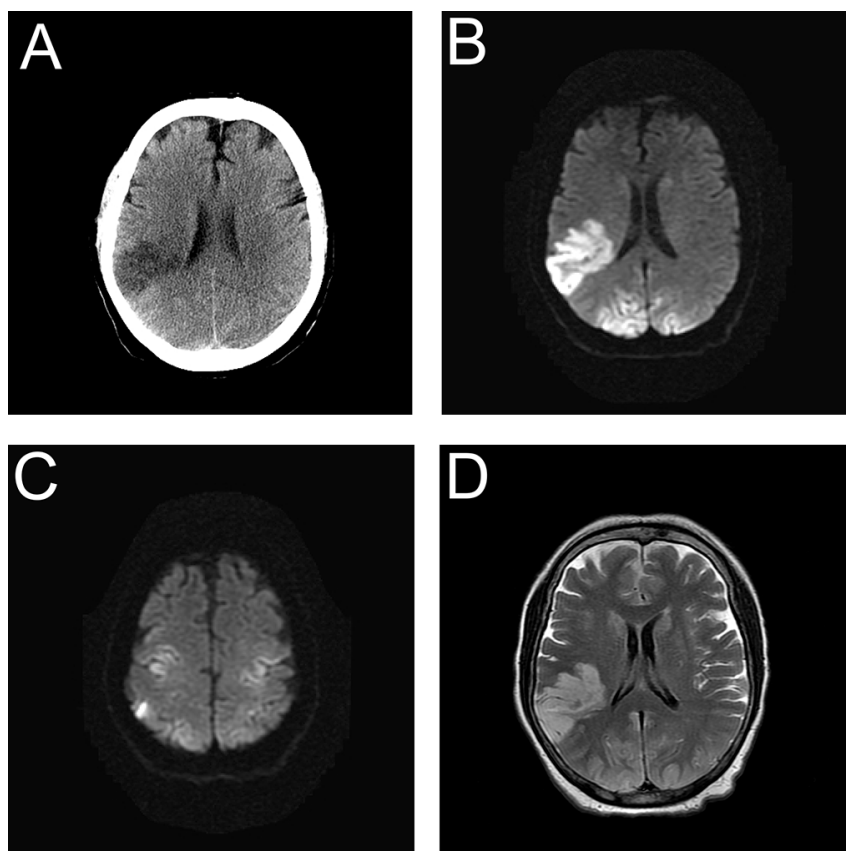

Figure 2 Imaging taken postoperative day 4. Cranial CT imaging (A) displays normal lateral ventricles and evidence of gadolinium-induced cytotoxic edema in the right parietal lobe (low attenuation). MRI DWI show gadolinium-induced cytotoxic edema in the right parietal lobe (B) corresponding to figure $2 \mathrm{~A}$. There is also evidence of gadoliniuminduced cytotoxic edema in the bilateral occipital region (B) and the bilateral parietal lobes (C). MRI FLAIR reveals cytotoxic edema in the right parietal lobe (D) corresponding to figure $2 \mathrm{~B}$. The bright signal indicates that gadolinium is still present in the sulci. DWI, diffusionweighted imaging; FLAIR, fluid-attenuated inversion recovery.

with borderline cavitation. On microscopic examination, the cerebellum displayed ischemic changes, and the hippocampus and lower pons displayed mild gliosis. The midbrain appeared primarily intact. Cause of death was determined to be encephalopathy caused by the combined factors of gadolinium neurotoxicity and hypoxic-ischemic encephalopathy following cardiopulmonary arrest with successful restoration of circulation.

\section{DISCUSSION AND REVIEW OF THE LITERATURE}

To our knowledge, we report the first case report documenting a death following acute GBCA neurotoxicity. ${ }^{16}$ In this case, the presence of intrathecal gadolinium confirmed by radiographic imaging suggests that the intrathecal space was inadvertently entered when performing the epidurogram for the MILD. The intrathecal administration of a GBCA resulted in acute neurotoxicity and encephalopathy, including a cascade of cardiovascular and neurologic consequences. The signs and symptoms presented in this case, including alterations in mental status, seizures, respiratory distress and tachycardia, correspond to previous animal research and clinical reports of gadolinium neurotoxicity (table 1). ${ }^{12}{ }^{16-21}$ However, to date, there has not been a reported case of death following the utilization of gadolinium for neuraxial interventional pain procedures. Below we discuss the safety concerns regarding the use of GBCAs for neuraxial interventional pain procedures.

\section{Gadolinium chemistry and relevant pharmacology}

Prior to considering the use of GBCAs as an alternative contrast agent for neuraxial interventional pain procedures, it is of critical 
Table 1 Previous cases of intrathecal gadolinium neurotoxicity

\begin{tabular}{|c|c|c|c|c|}
\hline Author & Procedure & $\mathrm{GBCA}^{*}$ dose used & Signs and symptoms & Outcome \\
\hline Arlt et al ${ }^{17}$ & CT myelogram. & $\begin{array}{l}\text { Gadopentetate dimeglumine } \\
20 \mathrm{~mL} \\
7 \mu \mathrm{mol} / \mathrm{g} \text { brain. } \dagger \ddagger\end{array}$ & $\begin{array}{l}\text { Confusion, nausea, vomiting, dysarthria, } \\
\text { somnolence, blurred vision, delirium, limb } \\
\text { ataxia, gaze-evoked nystagmus, aggressive } \\
\text { behavior, visual and auditory hallucination and } \\
\text { incomplete anterograde amnesia. }\end{array}$ & $\begin{array}{l}\text { Day 4: regained alertness } \\
\text { Day 7: resolved behavioral disturbances and } \\
\text { psychotic symptoms } \\
\text { Day 10: discharged } \\
\text { Day 56: persistent concentration difficulties }\end{array}$ \\
\hline Li et $a l^{18}$ & MRI myelography. & $\begin{array}{l}\text { Gadopentetate dimeglumine } \\
15 \mathrm{~mL} \\
5.35 \mu \mathrm{mol} / \mathrm{g} \text { brain. } \dagger \ddagger\end{array}$ & $\begin{array}{l}\text { Headache, nausea, vomiting, coma and } \\
\text { systemic seizures. }\end{array}$ & $\begin{array}{l}\text { Day 8: regained consciousness } \\
\text { Day 22: discharged } \\
\text { Day 60: no reported side effects }\end{array}$ \\
\hline Kapoor et al ${ }^{19}$ & Epidural steroid injection. & $\begin{array}{l}\text { Gadodiamide } \\
4 \mathrm{~mL} \\
1.43 \mu \mathrm{mol} / \mathrm{g} \text { brain. } \dagger\end{array}$ & $\begin{array}{l}\text { Mental status changes, grand-mal seizure, } \\
\text { respiratory distress, agitation, hyperglycemia, } \\
\text { sinus tachycardia, respiratory acidosis, } \\
\text { metabolic alkalosis and amnesia. }\end{array}$ & $\begin{array}{l}\text { Day 8: responded to verbal commands and } \\
\text { improved pulmonary function } \\
\text { Day 10: discharged } \\
\text { Day } 182 \text { ( } 6 \text { months): complained of partial } \\
\text { seizure-like activity }\end{array}$ \\
\hline Park et $a l^{20}$ & CT myelogram. & $\begin{array}{l}\text { Gadopentetate dimeglumine } \\
6 \mathrm{~mL} \\
2.14 \mu \mathrm{mol} / \mathrm{g} \text { brain. } \dagger \ddagger\end{array}$ & $\begin{array}{l}\text { Confusion, global aphasia, vomiting, stupor, } \\
\text { severe rigidity, intermittent seizures, fever and } \\
\text { high blood pressure. }\end{array}$ & $\begin{array}{l}\text { Day 4: improved cognition } \\
\text { Day 15: discharged } \\
1 \text { month: complained of visual disturbances }\end{array}$ \\
\hline Nayak et a/16 & $\begin{array}{l}\text { Administered through side port } \\
\text { of an intraventricular catheter. }\end{array}$ & $\begin{array}{l}\text { Gadopentetate dimeglumine } \\
10 \mathrm{~mL} \\
3.57 \mu \mathrm{mol} / \mathrm{g} \text { brain. }{ }^{\dagger}\end{array}$ & $\begin{array}{l}\text { Agitation, labile blood pressure, aphasia, } \\
\text { dysarthria, depressed mentation, right facial } \\
\text { droop and increased urine output. }\end{array}$ & $\begin{array}{l}\text { Day 5: performed lumbar CSF drain } \\
\text { Day 26: required a tracheostomy for } \\
\text { ventilatory support } \\
2 \text { months: still in intensive care. Resolution } \\
\text { of the intraventricular GBCA }\end{array}$ \\
\hline Reeves et $\mathrm{al}^{21}$ & $\begin{array}{l}\text { Intrathecal catheter contrast } \\
\text { study. }\end{array}$ & $\begin{array}{l}\text { Gadobutrol } \\
2 \mathrm{~mL} \\
1.43 \mu \mathrm{mol} / \mathrm{g} \text { brain. }\end{array}$ & $\begin{array}{l}\text { Severe spastic pain and spasms in lower } \\
\text { extremities. }\end{array}$ & Day 28: no sequelae \\
\hline Popescu et al ${ }^{12}$ & $\begin{array}{l}\text { L4-L5 interlaminar epidural } \\
\text { steroid injection. }\end{array}$ & $\begin{array}{l}\text { Gadobutrol } \\
1.5 \mathrm{~mL} \\
1.07 \mu \mathrm{mol} / \mathrm{g} \text { brain. } \dagger\end{array}$ & $\begin{array}{l}\text { Vomiting, seizure activity, impaired } \\
\text { consciousness and respiratory compromise } \\
\text { requiring intubation. }\end{array}$ & Day 1: extubated and made full recovery \\
\hline
\end{tabular}

* In this column, volume of GBCA administered is provided alongside the estimated concentration of gadolinium per gram of brain. Calculated using $1400 \mathrm{~g}$ as the average weight of the human brain in order to be consistent with calculations from Arlt et al..$^{17}$

tIntrathecal administration was unintentional.

fUnintentional intrathecal administration was due to drug error.

GBCA, gadolinium-based contrast agent.

importance that interventional pain physicians understand relevant gadolinium chemistry, basic mechanisms of action, pharmacology and toxicity. Gadolinium is a trivalent lanthanide ion $\left(\mathrm{Gd}^{3+}\right) .{ }^{122}$ Free gadolinium ions are toxic. In GBCAs, the gadolinium ions are bound tightly to chelating agents to form a stable complex that reduces the toxicity of the parent compound. ${ }^{23}$ The chelating ligand limits the dissociation of the toxic gadolinium ion $\left(\mathrm{Gd}^{3+}\right)$ from the ligand during both the shelf-life and the in vivo time periods. ${ }^{23}$ Gadolinium has nine coordination sites; eight sites consist of the bond between gadolinium and the chelating ligand and the ninth consists of a coordinate bond between gadolinium and the oxygen atom of a water molecule. ${ }^{23}$

GBCAs (table 2) are structurally classified as macrocyclic or linear (open chain) based on the chelating ligand and further subdivided into ionic and non-ionic compounds. ${ }^{23}$ Macrocyclic GBCAs are considered more stable (ie, the gadolinium ion is more tightly bound to the chelating agent) and are associated with a lower dissociation constant (ie, slower dissociation) and a lower likelihood of dechelation (ie, release of the free gadolinium ion) in comparison to linear GBCAs. ${ }^{23}{ }^{24}$ Ionic GBCAs dissociate

Table 2 Prescribing information of different brands of gadolinium ${ }^{23}$

\begin{tabular}{|c|c|c|c|c|c|}
\hline Trade name & Generic name & Structure & $\begin{array}{l}\text { Documents the risk of } \\
\text { serious nervous system- } \\
\text { related complications? }\end{array}$ & $\begin{array}{l}\text { Presents information } \\
\text { regarding intrathecal } \\
\text { injection? }\end{array}$ & $\begin{array}{l}\text { Molar } \\
\text { concentration } \\
\text { of gadolinium } \\
\text { (mol/L) }\end{array}$ \\
\hline Ablavar $^{58}$ & Gadofosveset trisodium & Linear ionic & No & No & 0.25 \\
\hline Dotarem $^{59}$ & Gadoterate meglumine & Macrocyclic ionic & Yes & No & 0.5 \\
\hline Eovist $^{60}$ & Gadoxetate disodium & Linear ionic & Yes & No & 0.25 \\
\hline Gadavist $^{61}$ & Gadobutrol & Macrocyclic nonionic & Yes & No & 1 \\
\hline Magnevist $^{62}$ & Gadopentetate dimeglumine & Linear ionic & Yes & No & 0.5 \\
\hline MultiHance $^{63}$ & Gadobenate dimeglumine & Linear ionic & Yes & $\mathrm{No}^{*}$ & 0.5 \\
\hline Omniscan ${ }^{64}$ & Gadodiamide & Linear non-ionic & Yest & Yesł & 0.5 \\
\hline Optimark ${ }^{65}$ & Gadoversetamide & Linear non-ionic & Yes & $\mathrm{No}^{*}$ & 0.5 \\
\hline ProHance ${ }^{66}$ & Gadoteridol & Macrocyclic non-ionic & Yes & No & 0.5 \\
\hline
\end{tabular}

* States that it is only for intravenous use.

†Specifically indicates the risk of neurotoxicity due to intrathecal administration.

¥States: 'Not for intrathecal use. Inadvertent intrathecal use of gadodiamide has occurred and caused convulsions, coma, sensory and motor neurologic deficits.' 
into charged particles when entering solutions and have a higher viscosity and osmolality in comparison to non-ionic GBCAs. ${ }^{2}$ In theory, non-ionic GBCAs may have lower levels of extravasation into soft tissues during intravenous administration. However, linear ionic GBCAs are more thermodynamically stable than linear non-ionic GBCAs and are less likely to undergo dechelation via transmetalation (ie, the exchange of organic groups between metals). ${ }^{24} 25$ Because GBCAs have different structural classifications, disassociation constants and thermodynamic and kinetic stability constants, the risk of gadolinium toxicity differs among available formulations. ${ }^{23}$

For neurotoxicity, dechelation resulting in the release of the gadolinium ion is a major concern. At physiologic $\mathrm{pH}$, unassisted dechelation of GBCAs is limited. ${ }^{23}$ In vivo, the major method of dechelation is through transmetalation where endogenous cations (eg, $\mathrm{Cu}^{2+}, \mathrm{Ca}^{2+}, \mathrm{Fe}^{3+}$ and $\mathrm{Zn}^{2+}$ ) compete and displace the gadolinium ion from the chelating agent. ${ }^{162326}$ When gadolinium is released from a GBCA, it is termed as unchelated, dechelated or disassociated. ${ }^{27}{ }^{28}$ In vivo, when gadolinium is released from a GBCA, it is typically not free, but rather it is bound to a molecule or chemical. These host molecules include precipitated oxides, hydroxides, carbonates or natural biologic chelating agents such as citrate, amino acids, peptides or proteins. ${ }^{28} \mathrm{~A}$ significant amount of the research examing gadolinium transmetalation examined the process involving intravenous use, not direct administration of GBCA into the CSF. ${ }^{22}$ The specific impact of transmetalation on gadolinium toxicity with intrathecal use is unclear.

\section{GBCAs use in interventional pain medicine}

In individuals with hypersensitivity reactions to iodine based radiographic contrast agents, GBCAs have been suggested as an alternative agent. $^{910121329}$ Currently, nine GBCAs (table 2) are approved for intravenous use as a contrast agent in MRI protocols. ${ }^{23}$ When used off label in the neuraxial space as an alternative to iodinated radiographic contrast media, GBCAs have an intrinsic ability to attenuate X-rays. Maus et $a l^{29}$ examined the relative conspicuity of eight GBCAs (gadofosveset trisodium, gadoterate meglumine, gadoxetate disodium, gadobutrol, gadopentetate dimeglumine, gadobenate dimeglumine, gadodiamide and gadoteridol). Based on the in vitro testing, radiographic contrast levels of each tested GBCA were proportional to the gadolinium molar concentration. Overall, the radiopacity of gadolinium is less than that of iodinated contrast agents. Of the GBCAs tested, gadobutrol had the highest molar concentration of gadolinium (table 2) and had the highest radiodensity. When compared with iodinated radiographic contrast media, gadobutrol's radiographic contrast level existed between iohexol 240 and $140 \mathrm{mg} / \mathrm{mL}$ in the $\mathrm{kVps}$ ranges tested $(70-125 \mathrm{kVp}){ }^{29}$

Both peer-reviewed published articles and pain textbooks have suggested that gadolinium may be used as an alternative to iodinated contrast agents for neuraxial pain procedures, often with minimal attention given to the risk of neurotoxicity. ${ }^{9-12}$ In addition, despite the limited experience of intrathecal administration (inadvertent and advertent) of gadolinium, it has been stated that it is safe when GBCAs are directly administered into the CSF. ${ }^{10} 11$ Regarding interventional pain procedures, Safriel et $\mathrm{al}^{8}$ published the largest case series to date, examining the use of gadolinium in 92 patients with iodinated radiographic contrast allergies. Their group performed 127 outpatient procedures including discograms, epidural steroid (cervical, thoracic and lumbar) injections via both the interlaminar and transforaminal routes, and facet and nerve root blocks (cervical and lumbar) injections. The gadolinium doses ranged from $0.2 \mathrm{~mL}$ to $15.83 \mathrm{~mL}$ (ie, three-level discogram). For epidural steroid injections, the gadolinium dose ranged from $1 \mathrm{~mL}$ to $5 \mathrm{~mL}$ and for nerve root blocks the dose ranged from $0.2 \mathrm{~mL}$ to $1 \mathrm{~mL}$ per level. The type of gadolinium used was gadodiamide (linear non-ionic; table 2). For the neuraxial procedures, the authors performed a gadolinium test injection to confirm location of the needle and to exclude intrathecal injection. The volume of the gadolinium test injection was not provided. The authors do not report any occurrences of intrathecal administration. Safriel et $a l^{8}$ concluded that gadolinium seems to be a safe alternative in spine management procedures in individuals at high risk for a reaction to radiographic iodinated contrast.

\section{Gadolinium toxicity}

Gadolinium toxicity can be aligned into four general categories: (1) acute toxicity, including allergic reactions, (2) subacute/ chronic response via cell mediated reactions (eg, NSF), (3) gadolinium storage condition (ie, gadolinium lies primarily inert within the body) and (4) gadolinium deposition disease that involves both acute and subacute components of the immune response. ${ }^{27}$ For all four categories, genetic and immune roles have been implicated. ${ }^{27}$ Immediate hypersensitivity reactions to GBCAs are rare and range from $1.5,8.3$ or 16 immediate allergic like adverse events per 10000 administrations for linear non-ionic, linear ionic and macrocyclic non-ionic GBCAs, respectively. ${ }^{4}$ Although rare, the immediate hypersensitivity reactions can be fatal. ${ }^{30}$ The major toxicity concern with intravenous administration of GBCAs is NSF (fibroproliferative disorder) in patients with pre-existing renal disease. Fibrotic lesions in individuals with NSF develop a few days to months after exposure to GBCAs. ${ }^{31}$ Typically, individuals with NSF develop abnormalities in the skin, including swelling and tightness, but the condition can also affect myofascial tissues and body organs including the lungs, diaphragm, myocardium and striated muscle. ${ }^{32}$ The role of GBCAs and the exact immune mechanism by which the fibrotic lesions are triggered is currently unknown. ${ }^{31} 32$ Linear GBCAs (eg, gadodiamide and gadopentetate dimeglumine) have been mainly implicated in the pathogenesis of NSF. ${ }^{26}$

Recently, much attention has been placed on gadolinium deposition. In 2015, the FDA released the safety communication on the risk of brain deposits with repeated use of intravenous administration of GBCAs for MRI. ${ }^{33}$ This safety communication was updated in $2017 .{ }^{34}$ Gadolinium deposition typically occurs in select areas of the brain including the dentate nuclei, thalamus, caudate nucleus and globus pallidus. ${ }^{35}{ }^{36}$ Gadolinium depositions have been seen with both linear and macrocyclic contrast agents although more often with the former. ${ }^{35} 36$ Iron has been suggested as playing a central role in transmetalation and gadolinium toxicity for both NSF and gadolinium deposition in the brain. ${ }^{26}$ The areas of the brain typically targeted with gadolinium deposition are intrinsically iron rich. ${ }^{26}$ In a vast majority of the literature, more attention has been paid to the potential risks following gadolinium deposition in the central nervous system (CNS) after repeated use rather than acute neurotoxicity following a single intrathecal use. Currently, the clinical consequences of gadolinium brain deposition after repeated intravenous gadolinium exposure is unknown. ${ }^{13} 34$

\section{Acute neurotoxicity}

Although gadolinium deposition and NSF are often the main concerns with the intravenous use of GBCAs, when GBCAs are used in relatively small volumes for neuraxial interventional pain 
procedures, the major concern is acute CNS neurotoxicity. When given intrathecally, the blood-brain barrier does not play a role, and no barrier exists at the pial surfaces to the passage of gadolinium. ${ }^{37} 38$ Entry into the brain parenchyma occurs by simple diffusion. When a GBCA is given intrathecally, the amount of brain penetration is variable and often difficult to estimate. ${ }^{39}$

The exact mechanism by which gadolinium induces neuron disorders and neurotoxicity is unknown. ${ }^{15}$ To date, multiple mechanisms for acute neurotoxicity and cell death have been suggested including: (1) impairment of mitochondrial function leading to induced oxidative stress that results in cell apoptosis, ${ }^{15}$ (2) stress-related endoplasmic reticulum alterations in signal transduction, ${ }^{40}$ (3) alteration in cell signal processes including protein synthesis and the cell redox state ${ }^{4142}$ and (4) inhibition of cellular calcium hemostasis and modulation of unfolded protein responses. ${ }^{43}$ Gadolinium competes with calcium and blocks voltage gated calcium channels at low concentrations. ${ }^{5}$ Gadolinium ions and calcium ions have similar atomic radii, 107.8 pm and $114 \mathrm{pm}$, respectively. The blocking of these voltage gated calcium channels results in multiple negative consequences including alterations in coagulation, inhibition of smooth, skeletal and cardiac muscle contraction and transmission of nerve impulses. ${ }^{544}$ Furthermore, the risk of CNS neurotoxicity is increased with gadolinium, because it remains in specific areas of the brain including the cortex, hypothalamus and hippocampus for an extended period of time. ${ }^{45}$ Below we will discuss both animal and human studies examining neurotoxicity with GBCAs.

\section{Animal studies examining neurotoxicity of GBCA intrathecal administration}

Multiple animal studies have examined intrathecal administration of GBCAs including gadodiamide (linear non-ionic), gadopentetate dimeglumine (linear ionic) and gadobenate dimeglumine (linear ionic). ${ }^{143846-49}$ In two studies, Ray et al ${ }^{1447}$ demonstrated dose-dependent GBCA-associated neurotoxic effects in mice. In the first study (table 3), intraventricular administration of gadobenate dimeglumine resulted in acute neurotoxicity over several hours (stereotyped movements and myoclonus) and medium-term neurotoxicity over several days (ataxia and tremor). ${ }^{14}$ The neurotoxicity was dose dependent with changes in behavior and twitching beginning at a concentration of $5 \mu \mathrm{mol} / \mathrm{g}$ brain, ataxia and fine muscular tremor beginning at $10 \mu \mathrm{mol} / \mathrm{g}$ brain and an increase in severity of these symptoms at $15 \mu \mathrm{mol} / \mathrm{g}$ brain. No adverse reactions were seen at concentrations of $2.5 \mu \mathrm{mol} / \mathrm{g}$ and $3.3 \mu \mathrm{mol} / \mathrm{g}$ brain. The myoclonic twitching was suggestive of focal seizure activity. In addition, neuropathologic changes developed over 24 hours with the reactive changes persisting for 42 days. Morphologic changes also developed at doses of 5 $\mu \mathrm{mol} / \mathrm{g}$ brain and higher. The early changes consisted of loss of oligodendroglia and astroglia and disintegration of the myelin sheath. Axons also showed necrotic changes. Morphologic changes most commonly occurred in the thalamus, hypothalamus, superior olivary nuclei and vestibular nuclei. Lesions were also found in the lumbar and cervical spinal cord at the gray and white matter junctions. The histopathologic analysis of the CNS demonstrated changes similar to those observed in human central pontine myelinolysis.

In a second animal study, Ray et $a l^{47}$ examined the neurotoxic potential of both gadodiamide and gadopentetate dimeglumine, and both agents were found to be neurotoxic. Gadodiamide also produced dose-dependent acute neurotoxicity and morphologic changes. The gadodiamide produced morphologic changes that were identified in the thalamus, caudate nucleus of the basal ganglia and cerebellum. The cerebellum was most sensitive to the effects of gadodiamide. Unlike gadopentetate dimeglumine, spinal cord lesions were not identified with the administration of gadodiamide. Both the acute neurotoxicity and morphologic changes were dose dependent with the behavioral changes occurring at $2.5-\mu \mathrm{mol} / \mathrm{g}$ brain and above. The morphologic changes began in the cerebellum at $1.25-\mu \mathrm{mol} / \mathrm{g}$ brain with the thalamic and caudate lesions occurring at higher doses, $10-\mu \mathrm{mol} / \mathrm{g}$ brain.

In a larger animal model (swine), neurotoxicity following intrathecal administration of either gadodiamide or gadopentetate dimeglumine was examined with concentrations ranging from $0.625 \mathrm{mmol} / \mathrm{L}$ to $500 \mathrm{mmol} / \mathrm{L}{ }^{49}$ In the animals that were given GBCA concentrations of $500 \mathrm{mmol} / \mathrm{L}$ with more cephalad locations of administration, somatomotor irritation and paresis occurred after 24 hours. No effects were seen at the lower concentrations.

Additional animal studies have displayed no signs of neurotoxicity. Toney et $a l^{46}$ examined neurotoxic potential of intrathecally administered gadopentetate dimeglumine in mice at a dose of $2.5 \mu \mathrm{mol} / \mathrm{g}$ brain and demonstrated no significant acute and subacute physiologic and histologic changes. Although, in some of the animal's neural tissue, abnormalities (gliosis and inflammation) were observed. Jinkins et $a l^{38}$ examined intrathecal gadopentetate dimeglumine in rabbits and did not demonstrate seizures or alterations in behavior. The intrathecal toxicity of gadobenate dimeglumine (linear non-ionic) at dosages of 50 and $80 \mu \mathrm{mol}$ were also studied in another rabbit model. ${ }^{48}$ Neurologic deficits and behavioral changes were not identified. In addition, the histologic examination of the cerebrum, brainstem and spinal cord did not show any signs of toxicity.

\section{Human studies examining neurotoxicity of GBCA intrathecal administration}

Although the use of GBCAs in the intrathecal space is not approved by the FDA and some manufacturers' prescribing information (table 1) warns of the risks of intrathecal administration, its utilization and safety have been suggested based on the reports of administration for intrathecal gadolinium-enhanced magnetic resonance myelography and cisternography. ${ }^{11}$ 50-53 When used in these applications, GBCAs are used in small volumes, often in the range of $0.2-0.5 \mathrm{~mL}$, but not exceeding $1 \mathrm{~mL}$. In addition, the GBCA is diluted either with CSF, iodinated-based contrast agents, or normal saline, and injected slowly (eg, $0.2 \mathrm{~mL}$ per second). ${ }^{1150}$ The procedure is performed to detect abnormalities in the CNS including CSF fistulas.

Even though some have suggested that the use of small volumes of intrathecal GBCAs is safe, acute gadolinium neurotoxicity from both deliberate and inadvertent intrathecal administration has been documented in humans, with signs symptoms that were similar to this case in clinical presentation and timing. ${ }^{12}{ }^{16-21}$ The details of these cases are summarized in table 1. Specifically, three cases have been reported where GBCAs were used for neuraxial interventional pain procedures. ${ }^{12} 1921$ Two of the cases involved inadvertent intrathecal administration when used for interlaminar epidural placement and one case involved the injection of a GBCA for an intrathecal pump catheter contrast study. Acute neurotoxicity signs and symptoms occurred in these cases with both linear and macrocyclic GBCAs and with approximate intrathecal GBCA concentrations ranging from $1.07 \mu \mathrm{mol} / \mathrm{g}$ brain to $7 \mu \mathrm{mol} / \mathrm{g}$ brain (tables 1 and 3). It should be noted that the $1.07 \mu \mathrm{mol} / \mathrm{g}$ brain concentration is less than half of the concentration $(2.5 \mu \mathrm{mol} / \mathrm{g}$ brain) found to be safe in animal models (table 3). 
Table 3 Comparison of gadolinium concentrations in previous cases of intrathecal use

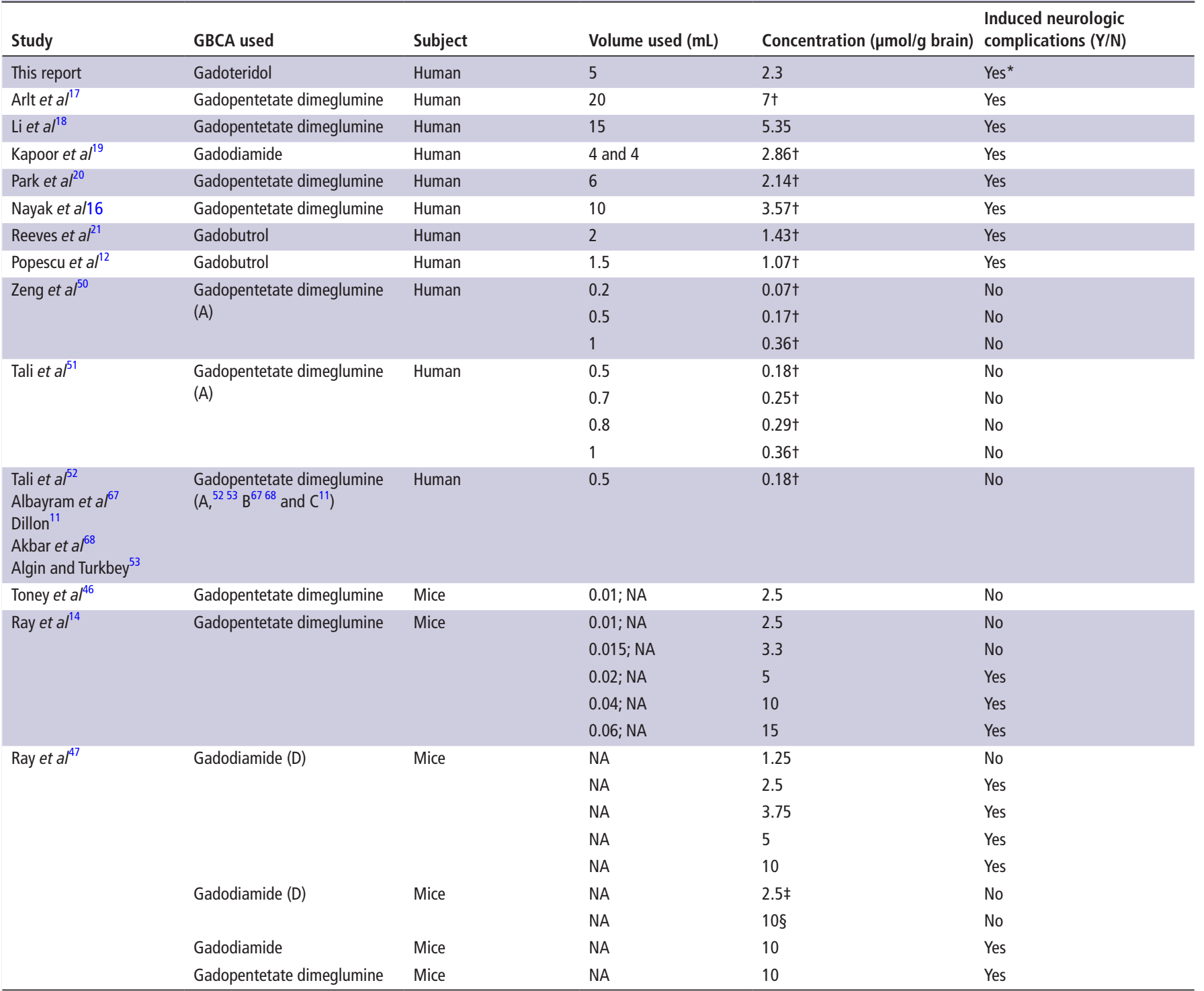

NA indicates not applicable because the volume relates to animal administration not human.

A: Mixed with CSF. B: Mixed with saline. C: Mixed with iohexol. D: Mixed with caldiamide.

Note: Only included publications that provided sufficient information to calculate concentration in $\mu$ mol gadolinium per gram of brain.

*Complications were lethal.

†Calculated using $1400 \mathrm{~g}$ as the average weight of the human brain in order to be consistent with calculations from Arlt et al. ${ }^{17}$

¥Delivered over 28 hours.

$\S$ Delivered over 112 hours.

GBCA, gadolinium-based contrast agent.

In many cases, GBCA acute neurotoxicity signs and symptoms were present within 1 hour of GBCA administration and included mental status changes, cognitive decline, involuntary movements, hallucinations and seizure activity.17; 18; 21 The rapid onset of neurotoxicity signs and symptoms also correlates with animal studies in which symptoms began within 28-220 min after injection. ${ }^{14}$ In addition, autonomic nervous system and cardiovascular symptoms were seen including hypertension, respiratory distress, tachycardia and fever. Signs and symptoms often resolved within days or weeks although extended sequelae were demonstrated in cases. ${ }^{161719}$ No cases of death from acute neurotoxicity were published prior to this report.

For the case reported here and in previous case reports where imaging was available, both CT and MRI demonstrated GBCA in the subarachnoid space (table 4). ${ }^{1216-21}$ The expected appearances of subarachnoid gadolinium in both CT and MRI imaging are shown in table 5 , and the examples of this contrast deposition in this case are demonstrated in figures 1 and 2. In both the case reported here and the Kapoor et $a l^{19}$ case, the gadolinium in the CSF was initially diagnosed as a subarachnoid hemorrhage. As demonstrated in table 5, gadolinium and subacute bleeding appear similar in both CT and MRI. Furthermore, gadolinium and acute bleeding appear similar in CT and T2 MRI sequences. If there is concern for inadvertent GBCA administration in the intrathecal space, it is essential that all members of the medical team, including the radiologist, are made aware to assist in early and appropriate detection.

Additionally, human studies demonstrate that intrathecal gadolinium directly deposits in the brain in both white and gray matter and that, with this form of delivery, the reduction in gadolinium 
Table 4 Image findings from previous cases of intrathecal gadolinium neurotoxicity

\begin{tabular}{|c|c|}
\hline Author & Image findings \\
\hline Arlt et al $\left.\right|^{17}$ & Gadolinium enhancement in the subarachnoid space 1 hour after injection, still present on day 4 . None detected on day 56. \\
\hline Li et $a l^{18}$ & $\begin{array}{l}\text { After } 6 \text { days: } \\
\text { FLAIR: enhancement in the CSF cisterns and cerebral sulci. } \\
\text { T1: enhancement in the CSF cisterns, cerebral sulci, cerebral cortex and deep parieto-occipital white matter. } \\
\text { T2: slight enhancement in the corona radiata and centrum semiovale. } \\
\text { DWI: hyperintensity in the right insular cortex, bilateral thalamus, basal ganglia and corona radiata. } \\
\text { ADC: hypointense signals in the cerebellum, brainstem, basal ganglia and cerebral cortex. } \\
\text { MRA: vasospasm in branches of the middle, anterior, and posterior cerebral arteries. } \\
\text { After } 8 \text { months: MRI still showed some enhancement; ADC and MRA were normal. }\end{array}$ \\
\hline Kapoor et al ${ }^{19}$ & FLAIR/T1-weighted images: hyperintensity in subarachnoid space and ventricles. \\
\hline Park et $a l^{20}$ & CT showed diffuse high density in subarachnoid space 6 hours after injection. CT normal after 4 days. \\
\hline Nayak et $a l^{16}$ & MR showed enhancement in the basal cisterns and leptomeninges. \\
\hline Reeves et $a^{21}$ & Enhancement visualized in intrathecal space during fluoroscopy. \\
\hline Popescu et al ${ }^{12}$ & $\mathrm{CT}$ and MRI showed enhancement visible in subarachnoid space same day as injection. \\
\hline
\end{tabular}

T1:T1-weighted MRI.

T2: T2-weighted MRI.

ADC, apparent diffusion coefficient map; CSF, cerebral spinal fluid; DWI, Diffusion weighted imaging; FLAIR, fluid-attenuated inversion recovery; MRA, MR angiography.

delivery to CNS tissue by the blood-brain barrier does not exist. $^{395455}$ In six patients who received intrathecal gadolinium (gadopentetate dimeglumine) without a prior history of administration of intravenous GBCA, Öner et $a l^{55}$ demonstrated the deposition of gadolinium in the deep nuclei of the brain. The glymphatic system (ie, the waste clearance system for the CNS) may assist in distributing the gadolinium throughout the brain. ${ }^{556}$

Besides anecdotal reports of providing steroids and performing CSF drainage, treatment is limited for the acute neurotoxicity associated with GBCAs. The treatments are predominantly supportive. Treatments also include the administration of anticonvulsants when seizures occur.

Our case, in addition to the animal studies and previous human reports, including the three neuraxial interventional pain medicine cases, raises significant concerns regarding the utilization of GBCAs as a radiographic contrast alternative in interventional pain medicine. First, acute GBCA neurotoxicity is significant and can result in long-term sequelae including death. Second, the safe dose limits $(2.5-\mu \mathrm{mol} / \mathrm{g}$ brain) suggested by animal studies for intrathecal GBCAs do not appear to directly correlate with humans. ${ }^{146}$ Toxicity in humans has occurred at doses of approximately $1-\mu \mathrm{mol} / \mathrm{g}$ brain and in the fatal case reported here, the patient only received approximately $2.3 \mu \mathrm{mol} / \mathrm{g}$ brain. ${ }^{12} \mathrm{Li}$ et al ${ }^{18}$ suggested that humans may be less tolerant to intrathecal gadolinium than animals; we are in agreement with this suggestion.

Recently, it was suggested that if a GBCA is used for an epidural procedure that the volume should not exceed $1 \mathrm{~mL}$. When performing epidural steroid injections under fluoroscopic guidance, there is the risk of inadvertent dural puncture (approximately $0.5 \%$ with the interlaminar approach). ${ }^{57}$ Physicians need to be aware that each GBCA has different pharmacologic properties and molar concentrations that do not allow for simplified volume limit across all GBCAs. In addition, if physicians want to stay below $1 \mu \mathrm{mol} / \mathrm{g}$ brain (ie, theoretical number based on case reports suggesting neurologic risk) depending on the molar concentration of gadolinium within the GBCA, this would allow volumes of injection between $1.4 \mathrm{~mL}$ ( $1 \mathrm{~mol} / \mathrm{L}$ of gadolinium) to $5.6 \mathrm{~mL}(0.25$ $\mathrm{mol} / \mathrm{L}$ of gadolinium). Furthermore, it must be remembered that the radiographic conspicuity increases with the molar concentration of gadolinium in the GBCA and that in order to make a GBCA provide adequate visualization, either a high molar concentration agent needs to be used at a low volume or a lower molar concentration needs to be used at a higher volume. The small volumes needed to stay at low GBCA concentrations in brain tissues may not be adequate for appropriate visualization.

\section{CONCLUSION}

In conclusion, gadolinium neurotoxicity is a serious risk and is often not considered when using a GBCA to assist with visualization in neuraxial interventional pain procedures. The use of GBCAs in the intrathecal and epidural spaces is not FDA approved, and as such, there is no clearly defined dose limit. Physicians must be aware that gadolinium poses a significant risk of acute neurotoxicity, even in very small doses. More research is required regarding the intrathecal use of each brand of gadolinium to determine a toxicity profile prior to consideration for use as radiographic contrast agent for neuraxial interventional pain procedures. We hope that any physician who chooses to use gadolinium off label will consider these risks when making that decision and also appropriately inform patients of the inherent risks of gadolinium use for neuraxial interventional pain procedures. Until further research is performed, we believe the use of gadolinium for neuraxial interventional pain procedures should

Table 5 Radiographic image characteristics of specific fluid in various imaging techniques

\begin{tabular}{llllll} 
& CT & MRI T1 & MRI T2 & MRI FLAIR & MRI DWI \\
\hline Cerebral spinal fluid & Dark & Dark & Bright & Dark & Dark \\
Gadolinium & Bright & Bright* & Dark & Bright & Bright \\
Acute blood/hemorrhage & Bright & Dark & Dark & Dark & N/A \\
\hline Subacute blood/hemorrhage & Bright & Bright & Dark & Bright & N/A \\
\hline
\end{tabular}

*The appearance of gadolinium on T1 images is concentration dependent. At lower concentrations, gadolinium is hyperintense (bright), and it becomes isointense then hypointense (dark) as the gadolinium concentration increases. T2 imaging is not concentration dependent.

DWI, diffusion-weighted imaging; FLAIR, fluid-attenuated inversion recovery. 
not be considered a viable and safe alternative when iodinated contrast agents are contraindicated.

Acknowledgements The authors would like to thank Kim Shaftner, MD, JD, for his assistance in preparing this report. We would like to thank the family of the patient for allowing us to publish this case report to further advance the education of the healthcare community.

Contributors All authors were involved in the analysis, synthesis and writing of this case report and the evidence-based review on gadolinium-based contrast agents.

Funding The authors have not declared a specific grant for this research from any funding agency in the public, commercial or not-for-profit sectors.

Competing interests None declared.

Patient consent for publication Not required.

Provenance and peer review Not commissioned; externally peer reviewed.

\section{REFERENCES}

1. Sherry $A D$, Caravan P, Lenkinski RE. Primer on gadolinium chemistry. J Magn Reson Imaging 2009;30:1240-8.

2. Lin S-P, Brown JJ. Mr contrast agents: physical and pharmacologic basics. J Magn Reson Imaging 2007;25:884-99.

3. Fraum TJ, Ludwig DR, Bashir MR, et al. Gadolinium-based contrast agents: a comprehensive risk assessment. J Magn Reson Imaging 2017;46:338-53.

4. Behzadi AH, Zhao Y, Farooq Z, et al. Immediate allergic reactions to gadolinium-based contrast agents: a systematic review and meta-analysis. Radiology 2018;286:471-82

5. Ramalho J, Semelka RC, Ramalho M, et al. Gadolinium-based contrast agent accumulation and toxicity: an update. Am J Neuroradiol 2016;37:1192-8.

6. Ramalho J, Ramalho M, Jay M, et al. Gadolinium toxicity and treatment. Magn Reson Imaging 2016:34:1394-8.

7. Durbhakula S, Cohen SP. Gadolinium use for interventional pain procedures: where we are and where we are heading. Reg Anesth Pain Med 2019;44:4-6.

8. Safriel Y, Ali M, Hayt M, et al. Gadolinium use in spine procedures for patients with allergy to iodinated contrast-experience of 127 procedures. Am J Neuroradiol 2006;27:1194-7.

9. Benzon HRS, Fishman S, Liu S, et al. Essentials of pain medicine. 3rd edn. Philadelphia, PA: Elsevier Saunders, 2011.

10. Benzon HRJ, CL W, Turk D, et al. Practical management of pain. 5th edn. Philadelphia, PA: Elsevier Mosby, 2014.

11. Dillon WP. Intrathecal gadolinium: its time has come? Am J Neuroradio/ 2008;29:3-4

12. Popescu A, Patel J, McCormick ZL, et al. Fact finders for patient safety: are gadoliniumbased contrast media safe alternatives to iodinated contrast agents for the safe performance of spinal injection procedures? Pain Med 2018;19:2089-90.

13. Benzon HT, Liu BP, Patel A, et al. Caution in using gadolinium-based contrast agents in interventional pain procedures. Anesth Analg 2018;127:1452-6.

14. Ray DE, Cavanagh JB, Nolan CC, et al. Neurotoxic effects of gadopentetate dimeglumine: behavioral disturbance and morphology after intracerebroventricular injection in rats. Am J Neuroradiol 1996;17:365-73.

15. Feng $X$, Xia Q, Yuan L, et al. Impaired mitochondrial function and oxidative stress in rat cortical neurons: implications for gadolinium-induced neurotoxicity. Neurotoxicology 2010;31:391-8.

16. Nayak NB, Huang JC, Hathout GM, et al. Complex imaging features of accidental cerebral intraventricular gadolinium administration. J Neurosurg 2013;118:1130-4.

17. Arlt S, Cepek L, Rustenbeck HH, et al. Gadolinium encephalopathy due to accidental intrathecal administration of gadopentetate dimeglumine. J Neurol 2007;254:810-2

18. Li L, Gao FQ, Zhang B, et al. Overdosage of intrathecal gadolinium and neurological response. Clin Radiol 2008;63:1063-8.

19. Kapoor R, Liu J, Devasenapathy A, et al. Gadolinium encephalopathy after intrathecal gadolinium injection. Pain Physician 2010;13:E321-6.

20. Park K-W, Im S-B, Kim B-T, et al. Neurotoxic manifestations of an overdose intrathecal injection of gadopentetate dimeglumine. J Korean Med Sci 2010;25:505-8.

21. Reeves C, Galang E, Padalia R, et al. Intrathecal injection of Gadobutrol: a tale of caution. J Pain Palliat Care Pharmacother 2017;31:139-43.

22. Caravan P, Ellison JJ, McMurry TJ, et al. Gadolinium(III) Chelates as MRI Contrast Agents: Structure, Dynamics, and Applications. Chem Rev 1999;99:2293-352.

23. Hao D, Ai T, Goerner F, et al. MRI contrast agents: basic chemistry and safety. J Magn Reson Imaging 2012:36:1060-71.

24. Runge VM. Dechelation (transmetalation): consequences and safety concerns with the linear gadolinium-based contrast agents, in view of recent health care Rulings by the EMA (Europe), FDA (United States), and PMDA (Japan). Invest Radiol 2018;53:571-8.

25. Ranga A, Agarwal Y, Garg KJ. Gadolinium based contrast agents in current practice: risks of accumulation and toxicity in patients with normal renal function. Indian J Radiol Imaging 2017;27:141-7.

26. Swaminathan S. Gadolinium toxicity: iron and ferroportin as central targets. Magn Reson Imaging 2016;34:1373-6.
27. Semelka RC, Ramalho M, Jay M. Summary of special issue on gadolinium bioeffects and toxicity with a look to the future. Magn Reson Imaging 2016;34:1399-401.

28. Tweedle MF. Gadolinium deposition: is it chelated or dissociated gadolinium? How can we tell? Magn Reson Imaging 2016;34:1377-82.

29. Maus TP, Schueler BA, Magnuson DJ, et al. Relative Conspicuity of gadolinium-based contrast agents in interventional pain procedures. Pain Med 2017;18:651-4.

30. Franckenberg S, Berger F, Schaerli S, et al. Fatal anaphylactic reaction to intravenous gadobutrol, a gadolinium-based MRI contrast agent. Radiol Case Rep 2018;13:299-301.

31. Edward M, Quinn JA, Burden AD, et al. Effect of different classes of gadolinium-based contrast agents on control and nephrogenic systemic Fibrosis-derived fibroblast proliferation. Radiology 2010;256:735-43.

32. Galan A, Cowper SE, Bucala R. Nephrogenic systemic fibrosis (nephrogenic fibrosing dermopathy). Curr Opin Rheumatol 2006;18:614-7.

33. FDA Drug Safety Communication. FDA evaluating the risk of brain deposits with repeated use of gadolinium-based contrast agents for magnetic resonance imaging (MRI). Available: https://www.fda.gov/Drugs/DrugSafety/ucm455386.htm [Accessed 19 Jan 2019].

34. FDA Drug Safety Communication. FDA warns that gadolinium-based contrast agents (GBCAs) are retained in the body; requires new class warnings. Available: https:// www.fda.gov/Drugs/DrugSafety/ucm559007.htm [Accessed 19 Jan 2019].

35. Gulani V, Calamante F, Shellock FG, et al. Gadolinium deposition in the brain: summary of evidence and recommendations. The Lancet Neurology 2017;16:564-70.

36. McDonald RJ, McDonald JS, Kallmes DF, et al. Intracranial gadolinium deposition after contrast-enhanced MR imaging. Radiology 2015;275:772-82.

37. Sage MR, Wilcox J, Evill CA, et al. Brain parenchyma penetration by intrathecal ionic and nonionic contrast media. Am J Neuroradiol 1982;3:481-3.

38. Jinkins JR, Williams RF, Xiong L. Evaluation of gadopentetate dimeglumine magnetic resonance cisternography in an animal model: preliminary report. Invest Radiol 1999:34:156-9.

39. Roman-Goldstein SM, Barnett PA, McCormick Cl, et al. Effects of gadopentetate dimeglumine administration after osmotic blood-brain barrier disruption: toxicity and MR imaging findings. Am J Neuroradiol 1991;12:885-90.

40. Xia Q, Feng $X$, Huang $H$, et al. Gadolinium-induced oxidative stress triggers endoplasmic reticulum stress in rat cortical neurons. J Neurochem 2011:117:38-47.

41. Erikson KM, Dobson AW, Dorman DC, et al. Manganese exposure and induced oxidative stress in the rat brain. Sci Total Environ 2004:334-335:409-16.

42. Lin AMY, Chao PL, Fang SF, et al. Endoplasmic reticulum stress is involved in arseniteinduced oxidative injury in rat brain. Toxicol Appl Pharmacol 2007:224:138-46.

43. Feng X-D, Xia Q, Yuan L, et al. Gadolinium triggers unfolded protein responses (UPRs) in primary cultured rat cortical astrocytes via promotion of an influx of extracellular Ca2+. Cell Biol Toxicol 2011;27:1-12.

44. Krause W, Press WR. Influence of contrast media on blood coagulation. Investigative Radiology 1997;32:249-59.

45. Feng L, Xiao H, He X, et al. Neurotoxicological consequence of long-term exposure to lanthanum. Toxicol Lett 2006;165:112-20.

46. Toney GM, Chavez HA, Ibarra R, et al. Acute and subacute physiological and histological studies of the central nervous system after intrathecal gadolinium injection in the anesthetized rat. Invest Radio/ 2001;36:33-40.

47. Ray DE, Holton JL, Nolan CC, et al. Neurotoxic potential of gadodiamide after injection into the lateral cerebral ventricle of rats. AJNR Am J Neuroradiol 1998; 19:1455-62

48. Kramer N, Berlis A, Klisch J, et al. Intrathecal gadolinium-enhanced MRcisternography: depiction of the subarachnoidal space and evaluation of gadobenatdimeglumin-(Gd-BOPTA, "Multihance") toxicity in an animal model and a clinical case. Acad Radiol 2002;9(Suppl 2):S447-51.

49. Skalpe I0, Tang GJ. Magnetic resonance imaging contrast media in the subarachnoid space. A comparison between gadodiamide injection and gadopentetate dimeglumine in an experimental study in pigs. Invest Radiol 1997;32:140-8

50. Zeng $\mathrm{Q}$, Xiong L, Jinkins JR, et al. Intrathecal gadolinium-enhanced Mr myelography and cisternography: a pilot study in human patients. AJR Am J Roentgenol 1999;173:1109-15.

51. Tali ET, Ercan N, Krumina G, et al. Intrathecal gadolinium (gadopentetate dimeglumine) enhanced magnetic resonance myelography and cisternography: results of a multicenter study. Invest Radiol 2002:37:152-9.

52. Tali ET, Ercan N, Kaymaz M, et al. Intrathecal gadolinium (gadopentetate dimeglumine)enhanced MR cisternography used to determine potential communication between the cerebrospinal fluid pathways and intracranial arachnoid cysts. Neuroradiology 2004:46:744-54.

53. Algin O, Turkbey B. Intrathecal gadolinium-enhanced Mr cisternography: a comprehensive review. Am J Neuroradiol 2013:34:14-22.

54. Evill CA, Wilson AJ, Fletcher MC, et al. Neurotoxicity of contrast media for magnetic resonance imaging after generalized breakdown of the blood-brain barrier. Acad Radiol 1996:3(Suppl 2):S336-8.

55. Öner AY, Barutcu B, Aykol Şükrü, Aykol S, et al. Intrathecal contrast-enhanced magnetic resonance Imaging-Related brain signal changes: residual gadolinium deposition? Invest Radiol 2017;52:195-7. 
56. Jessen NA, Munk ASF, Lundgaard I, et al. The Glymphatic system: a beginner's guide. Neurochem Res 2015;40:2583-99.

57. Manchikanti L, Malla Y, Wargo BW, et al. A prospective evaluation of complications of 10,000 fluoroscopically directed epidural injections. Pain Physician 2012;15:131-40.

58. ABLAVAR. (gadofosveset trisodium) [package insert]. North Billerica, MA: Lantheus Medical Imaging,Inc, 2013.

59. DOTAREM. (gadoterate meglumine) [package insert]. Bloomington, IN: Guerbet LLC, 2014

60. EOVIST. (gadoxetate disodium) [package insert]. Whippany, NJ: Bayer HealthCare Pharmaceuticals Inc, 2015.

61. GADAVIST. (gadobutrol) [package insert]. Whippany, NJ: Bayer HealthCare Pharmaceuticals Inc, 2016.

62. MAGNEVIST. (gadopentetate dimeg/umine) [package insert]. Whippany, NJ: Bayer HealthCare Pharmaceuticals Inc, 2016.
63. MultiHance. (gadobenate dimeg/umine) [package insert]. Bracco Diagnostics Inc: Princeton, NJ, 2010.

64. OMNISCAN. (gadodiamide) [package insert]. GE Healthcare Inc: Princeton, NJ, 2013.

65. OPTIMARK. (gadoversetamide) [package insert]. Raleigh, NC: Mallinckrodt Pharmaceuticals, 2014.

66. ProHance. (gadoteridol) [package insert]. Monroe Township, NJ: Bracco Diagnostics Inc, 2013.

67. Albayram S, Kilic F, Ozer H, et al. Gadolinium-enhanced Mr cisternography to evaluate dural leaks in intracranial hypotension syndrome. AJNR Am J Neuroradiol 2008:29:116-21.

68. Akbar JJ, Luetmer PH, Schwartz KM, et al. The role of Mr myelography with intrathecal gadolinium in localization of spinal CSF leaks in patients with spontaneous intracranial hypotension. Am J Neuroradiol 2012;33:535-40. 


\section{Correction: Fatal gadolinium-induced encephalopathy following accidental intrathecal administration: a case report and a comprehensive evidence-based review}

Provenzano DA, Pellis Z, DeRiggi L, et al. Fatal gadolinium-induced encephalopathy following accidental intrathecal administration: a case report and a comprehensive evidence-based review. Reg Anesth Pain Med 2019;44:721-9. doi:10.1136/rapm-2019-100422

Under the 'Acute neurotoxicity' paragraph on page 725 , the last paragraph, point four, states cellular calcium hemostasis, and should read cellular calcium homeostasis.

(c) Author(s) (or their employer(s)) 2019. No commercial re-use. See rights and permissions. Published by BMJ.

Reg Anesth Pain Med 2019;44:908. doi:10.1136/rapm-2019-100422corr1

D) Check for updates 